\title{
A preliminary study of the effect of ECRG4 overexpression on the proliferation and apoptosis of human laryngeal cancer cells and the underlying mechanisms
}

\author{
JIANPING JIA ${ }^{1,2}$, SONG DAI $^{2}$, XINGHE SUN ${ }^{2}$, YUEHONG SANG ${ }^{2}$, ZHENMING XU $^{2}$, \\ JIE ZHANG ${ }^{2}$, XIAOFENG CUI ${ }^{2}$, JINHUI SONG ${ }^{2}$ and XING GUO ${ }^{1}$ \\ ${ }^{1}$ Department of Otolaryngology-Head and Neck Surgery, The First Affiliated Hospital of China Medical University, \\ Shenyang, Liaoning 110001; ${ }^{2}$ Department of Otolaryngology, The 463 Hospital of Chinese PLA, \\ Shenyang, Liaoning 110042, P.R. China
}

Received September 16, 2014; Accepted June 3, 2015

DOI: $10.3892 / \mathrm{mmr} .2015 .4059$

\begin{abstract}
Human esophageal cancer-related gene 4 (ECRG4) is a potential tumor suppressor gene isolated from human esophageal epithelial cells. Studies have shown that ECRG4 effectively inhibits the proliferation of tumor cells and induces apoptosis. However, the role of ECRG4 in laryngeal cancer has not yet been clearly defined. In this study, a human laryngeal cancer cell line stably overexpressing ECRG4 was established. The effect of ECRG4 on the proliferation and apoptosis of laryngeal cancer cells and the associated mechanisms were investigated. The Hep-2 human laryngeal carcinoma cell line exhibited a low basal level of ECRG4 expression and was selected for the present study. The eukaryotic expression plasmid pcDNA3.1-ECRG4 was constructed and introduced into Hep-2 cells by transfection reagents. Western blot analysis, reverse transcription-quantitative polymerase chain reaction and immunofluorescence staining confirmed high-level expression of ECRG4. The 3-(4, 5-dimethylthiazol-2-yl)-2,5-diphenyltetrazolium bromide assay and colony formation assay showed that ECRG4 overexpression suppressed the proliferative capacity of laryngeal cancer cells in vitro. Cell cycle analysis showed that ECRG4 induced cell cycle arrest at the G0/G1 phase. Flow cytometric analysis and Hoechst staining demonstrated that overexpression of ECRG4 significantly induced apoptosis. Western blot analysis confirmed that $\mathrm{Bcl}-2$-associated $\mathrm{X}$ protein, cleaved-caspase- 3 and cleaved-poly (ADP-ribose) polymerase were upregulated in the apoptotic process, whereas
\end{abstract}

Correspondence to: Dr Xing Guo, Department of Otolaryngology-Head and Neck Surgery, The First Affiliated Hospital of China Medical University, 155 North Nanjing Street, Shenyang, Liaoning 110001, P.R. China

E-mail: guoxingyx1@outlook.com

Key words: human esophageal cancer-related gene 4, laryngeal cancer, Hep-2 cells, proliferation, apoptosis
B-cell lymphoma 2 was downregulated. In conclusion, overexpression of ECRG4 inhibited laryngeal cancer cell proliferation and induced cancer cell apoptosis. Therefore, ECRG4 exhibits potential as an effective target in gene therapy for laryngeal cancer.

\section{Introduction}

Laryngeal cancer is a type of malignancy that originates in the epithelial tissue of laryngeal mucosa. Laryngeal cancer constitutes $2.4 \%$ of all cancers. It is one of the most common malignant tumors of the head and neck region, ranking third after nasopharyngeal cancer and sinonasal cancer $(1,2)$. With increasing industrialization and air pollution, the worldwide incidence of laryngeal cancer has shown a gradually increasing trend (3). In the last 30 years, novel surgical procedures, new chemotherapeutic agents, more advanced radiotherapy and targeted drugs have been applied in the treatment of laryngeal cancer. However, the overall survival rate of laryngeal cancer patients has shown little improvement (4). Therefore, investigation of the mechanisms underlying the proliferation and apoptosis of laryngeal cancer cells is of particular importance to the development of novel and more effective treatments for laryngeal cancer so as to reduce the rate of mortality.

Human esophageal cancer-related gene 4 (ECRG4) is a tumor suppressor gene that was initially identified and cloned from human esophageal epithelial cells in 1998. ECRG4 is widely expressed in normal human tissues (5). However, ECRG4 expression is downregulated or lost in esophageal squamous cell carcinoma tissues and cell lines (6). Studies have found that in patients with breast cancer, the ECRG4 mRNA expression level is positively correlated with the survival rate and overall survival time (7). Similar results have been obtained from patients with esophageal cancer (8) and prostate cancer (9). ECRG4 has been shown to inhibit the growth of colon cancer cells, esophageal cancer cells and glioma cells through the induction of cell cycle arrest (10-12). Knockout of the ECRG4 gene in zebrafish embryos using RNA interference technology results in an enhanced capacity 
for cell proliferation (13). In addition, ECRG4 is closely associated with apoptosis in a variety of tumor cells (14-16). However, the effect of ECRG4 on the proliferation and apoptosis of laryngeal cancer cells and its mechanisms are not yet clear.

In the present study, an ECRG4-overexpressing laryngeal cancer cell line was obtained after G418 screening. The effect of ECRG4 overexpression on the proliferation and apoptosis of laryngeal carcinoma cells was assessed.

\section{Materials and methods}

Cell lines. Hep-2 and LSC-1 human laryngeal cancer cell lines (Wanleibio, Shenyang, China) were cultured in RPMI-1640 medium (Gibco, Grand Island, NY, USA) containing 10\% fetal bovine serum (FBS, HyClone, Logan, UT, USA). The cells were passaged by trypsinization when they reached $80-90 \%$ confluence.

Constructionofthe ECRG4 overexpressionvectorandselection of the stably transfected cell line. The following primers were designed for amplification of the coding region of the ECRG4 gene: ECRG4-F, 5'-ATAGAAGCTTGCCCCTCGCCCTC-3' (HindIII restriction site underlined); and ECRG4-R, 5'-CCGGATCCTCAGAAACCAAGTAGTG-3' (BamHI restriction site underlined). The human cDNA preserved in the laboratory was utilized as the template. The amplified ECRG4 gene was ligated into the pcDNA3.1 plasmid (Invitrogen Life Technologies, Carlsbad, CA, USA). The recombinant plasmid, pcDNA3.1-ECRG4, was digested with HindIII and BamHI, according to the manufacturer's instructions (Fermentas, Ontario, Canada). The recombinant plasmid was sequence-analyzed by Sangon Biotech (Shanghai, China). After the double restriction analysis and sequence analysis, the correct recombinant plasmid was termed pcDNA3.1-ECRG4. Logarithmically growing Hep-2 cells were seeded into 6-well plates. Upon reaching $\sim 80 \%$ confluence, the cells were transfected with pcDNA3.1-ECRG4 or negative control (pcDNA3.1 plasmid; Invitrogen Life Technologies) using Attractene Transfection Reagent (Qiagen, Shanghai, China) according to the manufacturer's instructions. At $24 \mathrm{~h}$ after transfection, the cells were subjected to $\mathrm{G} 418$ selection $(400 \mu \mathrm{g} / \mathrm{ml}$, Invitrogen Life Technologies). After 7-14 days, positive clones were selected and ECRG4 expression was examined.

Reverse transcription-quantitative polymerase chain reaction (RT-qPCR). Total RNA was extracted from all groups of cells using the total RNA extraction kit (Tiangen Biotech, Beijing, China) according to the manufacturer's instructions. Total RNA was reverse transcribed into cDNA and then subjected to quantitative fluorescence analysis on the Exicycler $^{\mathrm{TM}} 96$ quantitative fluorescence analyzer (Bioneer, Daejeon, Korea) using the SYBR Green MasterMix (Solarbio, Beijing, China). RT-qPCR was performed in a volume of $20 \mu \mathrm{l}$, containing $0.5 \mu \mathrm{l}$ each primer $(10 \mu \mathrm{M}), 1 \mu \mathrm{l} \mathrm{cDNA}$

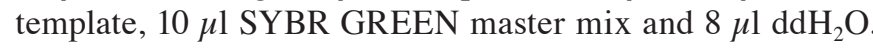
Thermal cycling conditions were as follows: Initial denaturation at $95^{\circ} \mathrm{C}$ for $10 \mathrm{~min}$; amplification for 40 cycles of $95^{\circ} \mathrm{C}$ for $10 \mathrm{sec}, 60^{\circ} \mathrm{C}$ for $20 \mathrm{sec}$ and $72^{\circ} \mathrm{C}$ for $30 \mathrm{sec}$. The mixture
Table I. Sequences of primers for reverse transcription-quantitative polymerase chain reaction.

\begin{tabular}{ll}
\hline Primer name & \multicolumn{1}{c}{ Sequence (5'-3') } \\
\hline ECRG4-F & AACGAGAAGCACCTGTTCCAA \\
ECRG4-R & TCGCCATAGTATTCATGTCCA \\
$\beta$-actin-F & CCATCGTCCACCGCAAAT \\
$\beta$-actin-R & GCTGTCACCTTCACCGTTC \\
\hline
\end{tabular}

ECRG4, esophageal cancer-related gene 4; F, forward; R, reverse.

was then cooled at $4^{\circ} \mathrm{C}$ for $5 \mathrm{~min}$. The internal control was $\beta$-actin and each sample was tested in triplicate. The $2^{-\Delta \Delta \mathrm{Ct}}$ method (17) was used for relative quantification of gene expression. The sequences of the primers are listed in Table I.

Western blot analysis. The total protein was extracted from all groups of cells, and the protein concentration was determined using the Bicinchoninic Acid Protein Assay kit (Beyotime Institute of Biotechnology, Haimen, China). Equal quantities of protein were loaded onto each lane, separated using 10 or $13 \%$ sodium dodecyl sulfate-polyacrylamide gel electrophoresis and transferred to polyvinylidene difluoride membranes (Millipore, Bedford, MA, USA). The membranes were incubated first with the following primary antibodies: Rabbit anti-human anti-ECRG4 polyclonal antibody (1:200; cat. no. sc-135139; Santa Cruz Biotechnology, Inc., Santa Cruz, CA, USA), rabbit anti-human anti-cleaved-caspase-3 polyclonal antibody (1:500; cat. no. bs-0081R; Bioss, Beijing, China), rabbit anti-human anti-cleaved-poly ADP-ribose polymerase (PARP) polyclonal antibody (1:200; cat. no. sc-23461-R; Santa Cruz Biotechnology, Inc.), rabbit anti-human anti-Bcl-2-associated X protein (Bax) polyclonal antibody (1:400; cat. no. BA0315; Boster, Wuhan, China) and rabbit anti-human anti-B-cell lymphoma $2(\mathrm{Bcl}-2)$ polyclonal antibody (1:400; cat. no. BA0412; Boster) at $4^{\circ} \mathrm{C}$ overnight. The membranes were washed four times with Tween-20 in Tris-buffered saline for $5 \mathrm{~min}$. They were then incubated with horseradish peroxidase-conjugated goat anti-rabbit IgG (1:5,000 dilution, Beyotime Institute of Biotechnology) for $45 \mathrm{~min}$ at $37^{\circ} \mathrm{C}$. After addition of the enhanced chemiluminescence (ECL) reagents (Qihai Biotec, Shanghai, China), the target proteins were visualized and scanned using Gel-Pro Analyzer software 4.0 (Media. Cybernetics, Inc., Bethesda, MD, USA). The detected proteins were normalized to $\beta$-actin.

Immunofluorescence staining. Cells grown on coverslips were fixed in $4 \%$ paraformaldehyde for $15 \mathrm{~min}$, permeabilized with $0.1 \%$ Triton $\mathrm{X}-100$ for 30 min and incubated with rabbit anti-human anti-ECRG4 polyclonal antibody (1:100; cat. no. sc-135139; Santa Cruz Biotechnology, Inc.) at $4^{\circ} \mathrm{C}$ overnight. The cells were then incubated with Cy3-labeled goat anti-rabbit secondary antibody (1:100 dilution; Beyotime Institute of Biotechnology) for $1 \mathrm{~h}$ at room temperature. 4',6-Diamidino-2-phenylindole (Biosharp, Hefei, China) was added drop-wise to completely cover the cells for nuclei staining. The coverslip with cells was inversely placed and mounted on a slide with anti-fluorescence quenching agent 

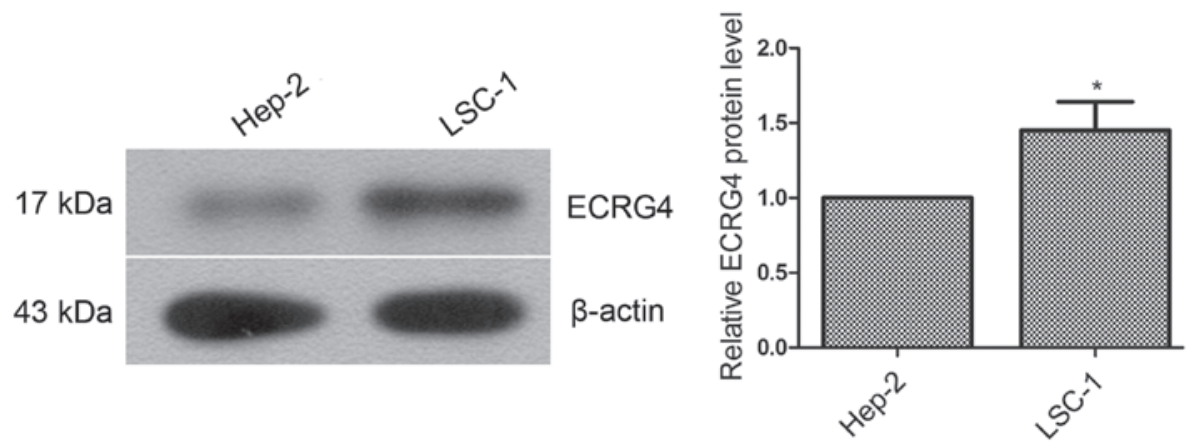

Figure 1. Selection of cell lines. The expression levels of ECRG4 in Hep-2 and LSC-1 human laryngeal cancer cell lines were examined by western blot analysis. Grayscale analysis was performed using $\beta$-actin as the internal control. Experimental data are expressed as the mean \pm standard deviation. ${ }^{*} \mathrm{P}<0.05$, compared with Hep-2 cells. ECRG4, human esophageal cancer-related gene 4.

(Solarbio). The staining results were observed under a laser scanning confocal microscope and imaged (FV1000S-SIM/IX81; Olympus, Tokyo, Japan).

Examination of cell proliferation using the 3-(4,5-dimethylthiazol-2-yl)-2,5-diphenyltetrazolium bromide (MTT) assay. Cells from each experimental group were plated in 96-well plates at a density of $2 \times 10^{3}$ cells/well. Five replica wells were set up for each experimental group. Blank control wells were also included. At days $0,1,2,3$ and 4 after cell inoculation, MTT solution (final concentration of $0.2 \mathrm{mg} / \mathrm{ml}$; Sigma-Aldrich, St. Louis, MO, USA) was added to each well containing cells. After incubation at $37^{\circ} \mathrm{C}$ for $5 \mathrm{~h}$, the supernatant was removed, and $200 \mu \mathrm{l}$ dimethylsulfoxide (Sigma-Aldrich) was added to each well to dissolve the purple crystals. The optical density at $490 \mathrm{~nm}\left(\mathrm{OD}_{490}\right)$ was determined using a microplate reader (ELX-800; Bio-TEK Instruments Inc, Winooski, VT, USA), and cell growth curves were constructed.

Colony formation assay. Cells from each group were seeded at $\sim 300$ cells per $60 \mathrm{~mm}$ Petri dish. The Petri dishes were incubated at $37^{\circ} \mathrm{C}$ and $5 \% \mathrm{CO}_{2}$ until visible colonies were formed. The colonies were fixed in $4 \%$ paraformaldehyde, stained with Wright-Giemsa staining reagent (Nanjing Jiancheng Bioengineering Institute, Nanjing, China) and observed under a microscope (AE31; Motic Electric, Xiamen, China). A cell cluster containing at least 50 cells was counted as a colony. The colony formation rate was calculated based on the following formula: Colony formation rate $(\%)=$ (number of colonies/number of seeded cells) x 100 .

Analysis of the cell cycle by flow cytometry. Cells were trypsinized, harvested and fixed in precooled $70 \%$ ethanol at $4^{\circ} \mathrm{C}$ for $2 \mathrm{~h}$. The fixed cells were centrifuged at $252 \mathrm{xg}$, resuspended in $500 \mu 1$ staining buffer and mixed thoroughly with $25 \mu 1$ propidium iodide (PI) staining solution according to the instructions of the kit (Beyotime Institute of Biotechnology). Subsequently, $10 \mu 1$ RNase A (Beyotime Institute of Biotechnology) was added to the cell suspension. After incubation at $37^{\circ} \mathrm{C}$ for $30 \mathrm{~min}$ in the dark, the cells were processed for flow cytometry (FACSCalibur; Becton, Dickinson and Company, USA).

Hoechst staining. Cells from each experimental group were seeded onto coverslips in 12 -well plates at a density of $3 \times 10^{4}$ cells/well and cultured for $48 \mathrm{~h}$ in an incubator at $37^{\circ} \mathrm{C}$ and $5 \%$ $\mathrm{CO}_{2}$. The cells were then fixed, stained with Hoechst solution (Beyotime Institute of Biotechnology), covered with drops of anti-quenching mounting solution and mounted onto microscope slides. The slides were observed under a fluorescence microscope (BX61; Olympus) and photographed.

Examination of apoptosis by flow cytometry. Cells were trypsinized, harvested and resuspended in $500 \mu 1$ Binding Buffer according to the instructions of the apoptosis detection kit (Wanleibio). A total of $5 \mu 1$ Annexin V-fluorescein isothiocyanate was added to the cell suspension and mixed thoroughly. Subsequently, $5 \mu \mathrm{l}$ PI was added. After incubation for $15 \mathrm{~min}$ at room temperature in the dark, the cells were analyzed by flow cytometry (FACSCalibur; Becton, Dickinson and Company) for determination of apoptosis rate.

Statistical analysis. Experimental data are expressed as the mean \pm standard deviation. Comparisons between the experimental groups were conducted using one-way analysis of variance. Multiple comparisons were conducted using the Bonferroni post hoc test. Data analysis and image processing were performed using the Graphpad Prism 5.0 software (GraphPad Software, Inc., San Diego, CA, USA). P $<0.05$ was considered to indicate a statistically significant difference.

\section{Results}

Selection of cell lines. To select a suitable human laryngeal cancer cell line for stable transfection and subsequent ECRG4 gene-related experiment, the total protein from Hep-2 and LSC-1 cells was extracted. The expression levels of ECRG4 in the two cell lines were examined using western blot analysis. The results showed that the ECRG4 expression level in Hep-2 cells was significantly lower than that in LSC-1 cells (Fig. 1, $\mathrm{P}<0.05$ ). To eliminate the effect of basal expression of ECRG4, Hep-2 cells were selected for subsequent experiments.

Establishment and identification of the cell line stably overexpressing ECRG4. To investigate the function of the ECRG4 gene, pcDNA3.1-ECRG4 was transfected into Hep-2 cells, and ECRG4 expression in positive cells was analyzed by western blot analysis and RT-qPCR. Cells transfected with empty pcDNA3.1 vector and parental cells were used as controls. 

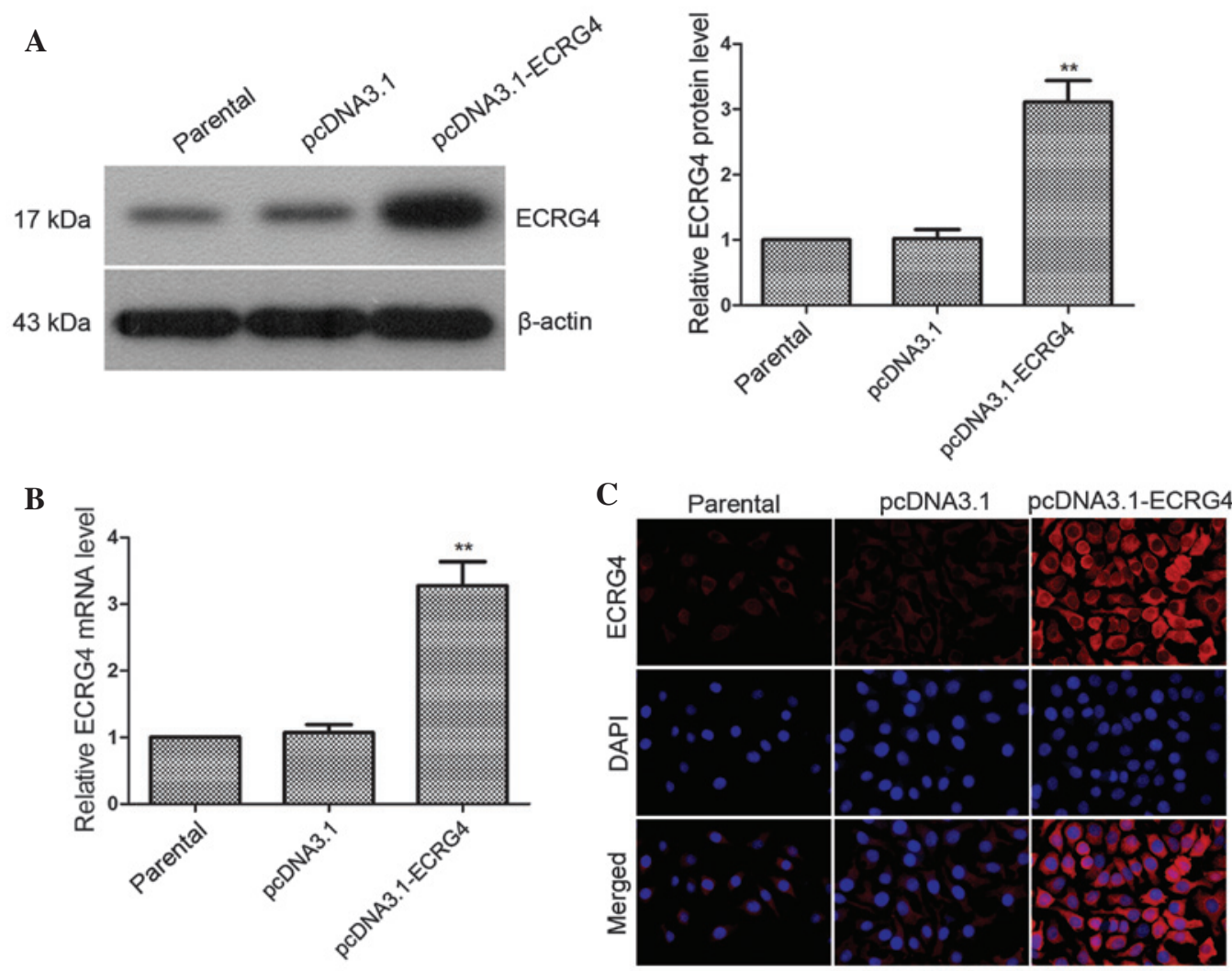

Figure 2. Establishment of a cell line stably overexpressing ECRG4. (A) Western blot analysis of ECRG4 protein expression. Grayscale analysis was conducted using $\beta$-actin as the internal control. (B) Reverse transcription-quantitative polymerase chain reaction analysis of ECRG4 mRNA expression. (C) Immunofluorescence examination of ECRG4 distribution. ECRG4 expression was visible under a fluorescence microscope (red). The nuclei were stained blue. Representative results of several replica experiments are shown in the figure (magnification, $x 600$ ). Experimental data are expressed as the mean \pm standard deviation. ${ }^{* *} \mathrm{P}<0.01$, compared with the pcDNA3.1 group. ECRG4, human esophageal cancer-related gene 4.

The results showed that the expression levels of ECRG4 protein and mRNA in the pcDNA3.1-ECRG4 group were increased by 3.05 (Fig. 2A, $\mathrm{P}<0.01$ ) and 3.07-fold (Fig. 2B, $\mathrm{P}<0.01)$, respectively, compared with the pcDNA3.1 group. The immunofluorescence staining results showed that ECRG4 expression was obviously elevated in the pcDNA3.1-ECRG4 group compared with the other two groups (Fig. 2C), which were consistent with the western blot analysis and RT-qPCR results. Thus, a laryngeal cancer cell line stably overexpressing ECRG4 was established.

ECRG4 overexpression inhibits the proliferation of laryngeal cancer cells. To investigate the effect of ECRG4 overexpression on the proliferative capability of laryngeal cancer cells, cell proliferative capability was examined using the MTT assay and colony formation assay. The results of the MTT assay showed that at day 2, day 3 and day 4 , the proliferative capability was severely impaired in the pcDNA3.1-ECRG4 group compared with the pcDNA3.1 group (Fig. 3A; day 2, $\mathrm{P}<0.05$; days 3 and $4, \mathrm{P}<0.01)$. The effect of ECRG4 on the clonogenic capacity of laryngeal cancer cells was further examined using the colony formation assay. The results showed that the colony formation rate in the pcDNA3.1-ECRG4 group was $45.27 \pm 7.19 \%$, which was lower than that in the pcDNA3.1 group $(83.07 \pm 7.51 \%)$. The results indicated that ECRG4 significantly reduced the colony formation ability of laryngeal cancer cells (Fig. 3B, P<0.01). This study further investigated the cell-cycle phase distribution in all three groups of cells using flow cytometry. As shown in Fig. 3C, the percentage of cells in the G0/G1 phase was significantly increased in the pcDNA3.1-ECRG4 group compared with that in the pcDNA3.1 group (71.7 vs. $39.41 \%, \mathrm{P}<0.01)$. By contrast, the percentage of cells in the $S$ phase and $\mathrm{G} 2 / \mathrm{M}$ phase were decreased markedly in the pcDNA3.1-ECRG4 group (S phase, 20.14 vs. $44.83 \%$, $\mathrm{P}<0.01$; and $\mathrm{G} 2 / \mathrm{M}$ phase, 8.17 vs. $15.76 \%, \mathrm{P}<0.05$, respectively). These results indicated that overexpression of ECRG4 inhibited laryngeal cancer cell proliferation and arrested cells in the G0/G1 phase of the cell cycle.

Overexpression of ECRG4 effectively induces apoptosis in laryngeal cancer cells. Cell apoptosis was measured by flow cytometry and fluorescence microscopy using Annexin V/PI and Hoechst staining, as well as the analysis of the expression of apoptosis-related factors. The results of flow cytometric analysis showed that the apoptotic rate was significantly elevated in the pcDNA3.1-ECRG4 group compared with the pcDNA3.1 group $(19.37 \pm 0.67$ vs. $0.66 \pm 0.09 \%$; Fig. $4 A$, $\mathrm{P}<0.01)$. Hoechst staining showed that compared with cells in the parental group and the pcDNA3.1 group, cells in the pcDNA3.1-ECRG4 group exhibited significantly increased chromatin condensation and more densely stained nuclei (Fig. 4B). To determine whether ECRG4-induced apoptosis of laryngeal cancer cells affected the expression of apoptosis-related factors, western blot analysis was performed to examine the expression of Bax, Bcl-2, cleaved-caspase- 3 and cleaved-PARP. The results showed that the expression levels of 


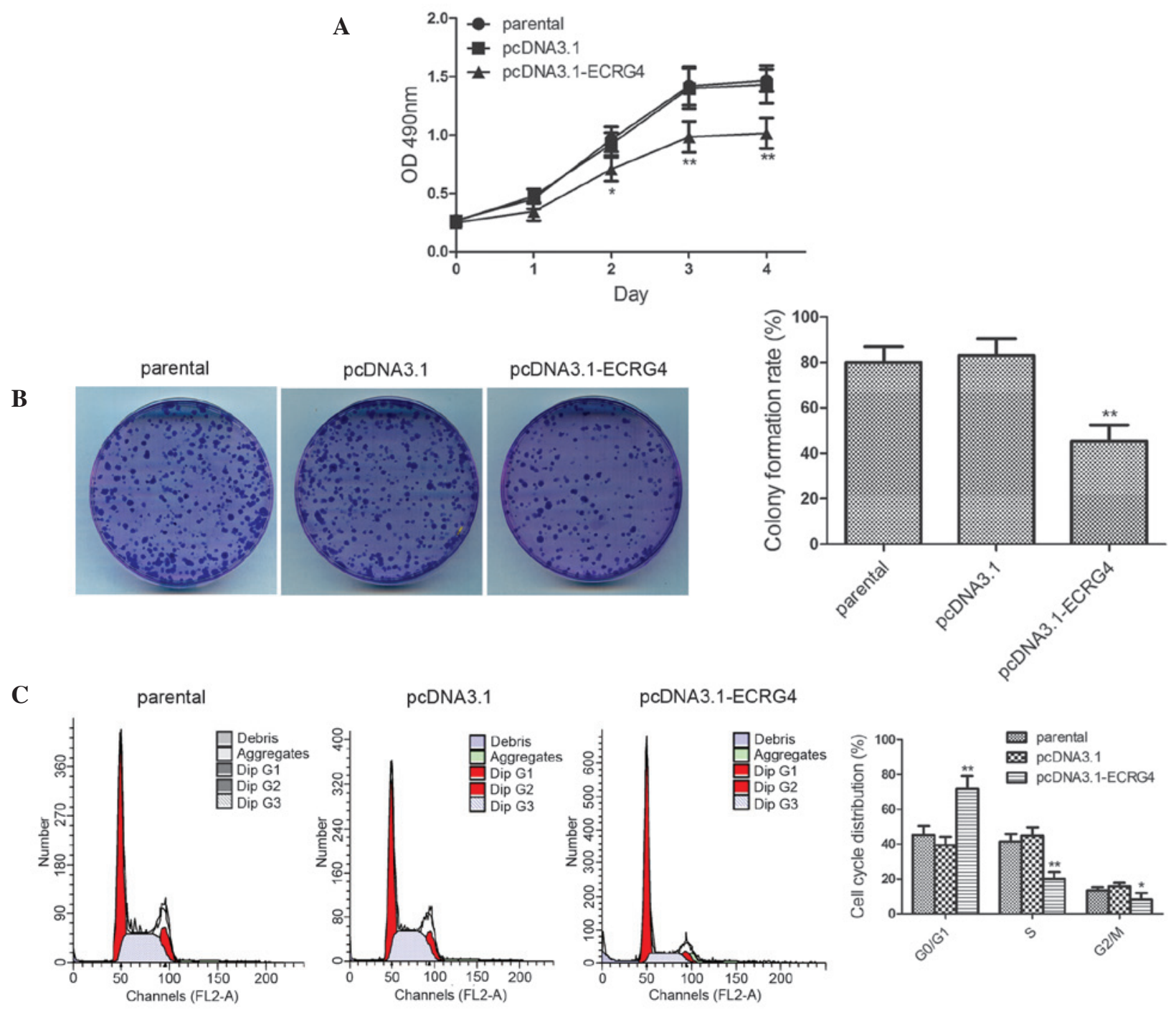

Figure 3. Overexpression of ECRG4 inhibited the proliferation of laryngeal cancer cells. (A) Examination of the proliferative capacity of laryngeal cancer cells by 3-(4,5-dimethylthiazol-2-yl)-2,5-diphenyltetrazolium bromide assay. Cells from the three experimental groups were seeded into 96-well plates. Five replica wells were set up for each experimental group. The $\mathrm{OD}_{490}$ values were measured at days $0,1,2,3$ and 4 after cell inoculation. (B) Determination of the clonogenic capacity of laryngeal cancer cells using colony formation assay. Cells from the experimental groups were seeded into Petri dishes. After day 14 of culture, the cells were fixed and the colony formation rates were calculated under a microscope. (C) Analysis of the cell cycle by flow cytometric analysis. Experimental data are presented as the mean \pm standard deviation. ${ }^{*} \mathrm{P}<0.05$, and ${ }^{* *} \mathrm{P}<0.01$, compared with the pcDNA3.1 group. ECRG4, human esophageal cancer-related gene 4 .

cleaved-PARP, cleaved-caspase-3 and Bax were significantly elevated in cells from the pcDNA3.1-ECRG4 group compared with that from the pcDNA3.1 group (Fig. 4 C, P<0.01). By contrast, the expression level of $\mathrm{Bcl}-2$ was markedly decreased $(\mathrm{P}<0.01)$. These results demonstrated that overexpression of ECRG4 significantly induced apoptosis in laryngeal cancer cells.

\section{Discussion}

ECRG4 is expressed at low or undetectable levels in a variety of malignant tumor tissues and cell lines. The expression level of ECRG4 is closely associated with tumor proliferation and apoptosis. However, the role of ECRG4 in laryngeal cancer has not been reported. In the present study, a laryngeal cancer cell line stably overexpressing ECRG4 was established. This study found that upregulation of ECRG4 induced cell cycle arrest and inhibited laryngeal cancer cell proliferation. In addition, upregulation of ECRG4 accelerated apoptosis in laryngeal cancer cells by regulating apoptosis-related factor expression. This study preliminarily clarified the role of ECRG4 in the proliferation and apoptosis of laryngeal cancer cells and its mechanisms during apoptosis.

The Hep-2 and LSC-1 cells were selected from the available human laryngeal cancer cell lines and the expression levels of ECRG4 were compared in the two cell lines. The results showed that the ECRG4 expression level in Hep-2 cells was significantly lower than that in LSC-1 cells. As high basal ECRG4 expression would interfere with subsequent experiments, Hep-2 cells were selected for further experiments.

Attenuated ECRG4 expression levels have been confirmed in esophageal squamous cell carcinoma (8), prostate cancer (9), colon cancer and glioma (10), while enhanced expression levels of ECRG4 were detected in normal tissues. ECRG4 
A
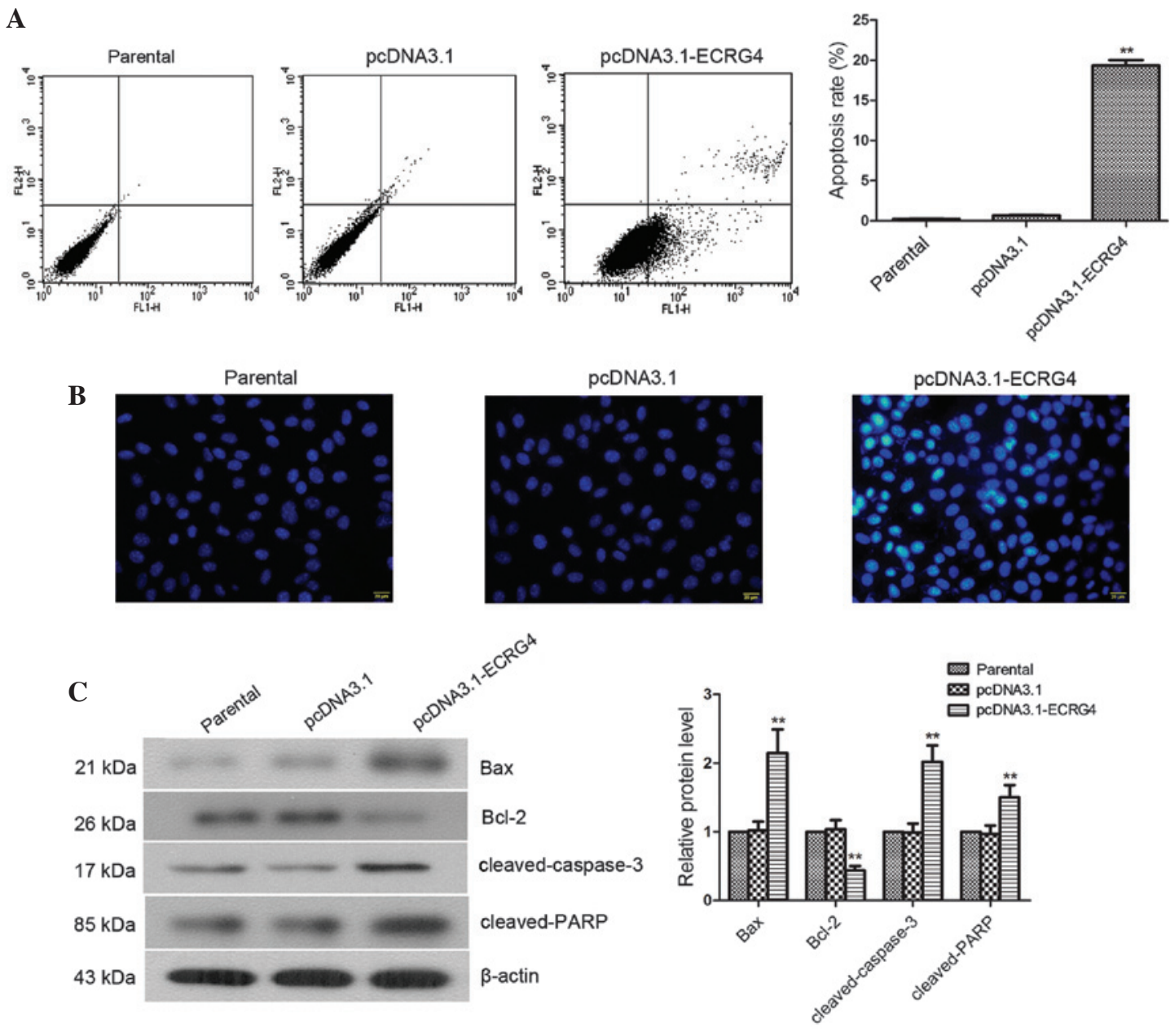

Figure 4. Overexpression of ECRG4 induced apoptosis in laryngeal cancer cells through regulation of the expression of apoptosis-related factors. (A) Examination of apoptosis by flow cytometric analysis. The figure shows the representative results of several repeated experiments. (B) Examination of apoptosis by Hoechst staining. Apoptotic cells exhibited intensive chromatin condensation and dense, strongly Hoechst stained nuclei (magnification, $\mathrm{x}$ 400). (C) Examination of the expression of Bax, Bcl-2, cleaved-caspase-3 and cleaved-PARP by western blot analysis. Grayscale analysis was performed using $\beta$-actin as the internal control. Experimental data are expressed as the mean \pm standard deviation. Compared with the pcDNA3.1 group, ${ }^{* *} \mathrm{P}<0.01$. ECRG4, human esophageal cancer-related gene 4; Bax, Bcl-2-associated X protein; Bcl-2, anti-B-cell lymphoma 2; PARP, poly ADP-ribose polymerase.

efficiently inhibits the growth of colon cancer cells, glioma cells and esophageal cancer cells. ECRG4 induces cell cycle arrest at the G0/G1 phase (10-12), which is hypothesized to be the key determinant that leads to proliferation inhibition in tumor cells (18-20). Based on the above findings, this study investigated the impact of ECRG4 on the proliferation and cell cycle of the human laryngeal cancer cells. The results showed that overexpression of ECRG4 significantly inhibited laryngeal cancer cells proliferation. Further cell cycle analyses by flow cytometry revealed that ECRG4 overexpression induced G0/G1 cell cycle arrest. The results demonstrated that ECRG4 inhibited the growth of laryngeal cancer cells through arresting cells in the G0/G1 phase and delaying cell cycle progression from the G0/G1 phase to the $S$ phase and G2/M phase. The present results are consistent with the findings of previous studies $(11,12)$.

Apoptosis can be initiated through the death receptor- or the mitochondria-dependent pathways (21). Stimulated by apoptotic signals, the proapoptotic member of the Bcl-2 family, Bax, undergoes a conformational change in the mitochondrial pathway of apoptosis. Bax translocates from the cytoplasm to the mitochondria and inserts into the mitochondrial membrane, which induces an increase in mitochondrial membrane permeability and results in the release of cytochrome $c$. Cytochrome $c$ then activates caspase-3, thereby inducing apoptosis (22). The level of Bcl-2, an important antiapoptotic protein, is correlated with tumor cell apoptosis. Bcl-2 is overexpressed in a variety of tumor cells, which conveys a certain degree of resistance to apoptosis-inducing drugs (23-25). Additionally, downregulation of Bcl-2 abolishes the resistance and promotes apoptosis in tumor cells $(26,27)$. The caspase family of proteases has been shown to exhibit a critical in apoptosis (28). Caspase-3 is a member of the caspase family and a key protease in apoptosis. Once activated, caspase- 3 triggers the activation of the downstream proteins and inevitably leads to apoptosis. Therefore, caspase-3 is known as the death protease (29). Caspase-3 is normally present in the cytoplasm in the form of an inactive zymogen. Apoptotic signals induce caspase-3 cleavage and activation through a variety of proteolytic enzymes, resulting in the generation of cleaved-caspase- 3 . PARP, the substrate of caspase- 3 , is activated and subsequently induces apoptosis (30-32). Studies have shown that ECRG4 effectively induces apoptosis in esophageal squamous cell carcinoma cells (14), head and neck squamous cell carcinoma 
cells (15) and gastric cancer cells (16); accompanied by upregulation of Bax and downregulation of Bcl-2 (15). This study further investigated whether ECRG4 overexpression induced apoptosis in human laryngeal cancer cells and examined the expression levels of a number of key apoptosis-related factors. The results of this study also demonstrated that overexpression of ECRG4 activated caspase-3 and PARP, and ultimately induced apoptosis through upregulating the expression of proapoptotic protein Bax and downregulating the expression of antiapoptotic protein Bcl-2.

In conclusion, ECRG4 suppresses the proliferation of laryngeal cancer cells through the induction of G0/G1 cell cycle arrest. In addition, ECRG4 induces apoptosis via regulation of the expression of Bax, Bcl-2, cleaved-caspase- 3 and cleaved-PARP. Therefore, overexpression of ECRG4 may become an effective gene therapy strategy for the treatment of laryngeal cancer.

\section{Acknowledgements}

This study was supported by a grant from the Medicine Summit Project of Liaoning Province (grant no. 4010218).

\section{References}

1. Hoffman HT, Porter K, Karnell LH, Cooper JS, Weber RS Langer CJ, Ang KK, Gay G, Stewart A and Robinson RA: Laryngeal cancer in the United States: changes in demographics, patterns of care and survival. Laryngoscope 116 (Suppl 111): $1-13,2006$

2. Jemal A, Siegel R, Ward E, Hao Y, Xu J and Thun MJ: Cancer statistics, 2009. CA Cancer J Clin 59: 225-249, 2009.

3. Jaseviciene L, Gurevicius R, Obelenis V, Cicenas S and Juozulynas A: Trends in laryngeal cancer incidence in Lithuania: A future perspective. Int J Occup Med Environ Health 17: 473-477, 2004

4. Almadori G, Bussu F, Cadoni G, Galli J, Paludetti G and Maurizi M: Molecular markers in laryngeal squamous cell carcinoma: Towards an integrated clinicobiological approach. Eur J Cancer 41: 683-693, 2005.

5. Matsuzaki J, Torigoe T, Hirohashi Y, Tamura Y, Asanuma H, Nakazawa E, Saka E, Yasuda K, Takahashi S and Sato N: Expression of ECRG4 is associated with lower proliferative potential of esophageal cancer cells. Pathol Int 63: 391-397, 2013.

6. Yue CM, Deng DJ, Bi MX, Guo LP and Lu SH: Expression of ECRG4, a novel esophageal cancer-related gene, downregulated by $\mathrm{CpG}$ island hypermethylation in human esophageal squamous cell carcinoma. World J Gastroenterol 9: 1174-1178, 2003.

7. Sabatier R, Finetti P, Adelaide J, Guille A, Borg JP, Chaffanet M, Lane L, Birnbaum D and Bertucci F: Down-regulation of ECRG4, a candidate tumor suppressor gene, in human breast cancer. PLoS One 6: e27656, 2011.

8. Mori Y, Ishiguro H, Kuwabara Y, Kimura M, Mitsui A, Kurehara H, Mori R, Tomoda K, Ogawa R, Katada T, et al: Expression of ECRG4 is an independent prognostic factor for poor survival in patients with esophageal squamous cell carcinoma. Oncol Rep 18: 981-985, 2007.

9. Vanaja DK, Ehrich M, Van den Boom D, Cheville JC, Karnes RJ, Tindall DJ, Cantor CR and Young CY: Hypermethylation of genes for diagnosis and risk stratification of prostate cancer. Cancer Invest 27: 549-560, 2009.

10. Götze S, Feldhaus V, Traska T, Wolter M, Reifenberger G, Tannapfel A, Kuhnen C, Martin D, Müller O and Sievers S: ECRG4 is a candidate tumor suppressor gene frequently hypermethylated in colorectal carcinoma and glioma. BMC Cancer 9: 447, 2009.
11. Li LW, Yu XY, Yang Y, Zhang CP, Guo LP and Lu SH: Expression of esophageal cancer related gene 4 (ECRG4), a novel tumor suppressor gene, in esophageal cancer and its inhibitory effect on the tumor growth in vitro and in vivo. Int J Cancer 125: 1505-1513, 2009.

12. Li W, Liu X, Zhang B, Qi D, Zhang L, Jin Y and Yang H: Overexpression of candidate tumor suppressor ECRG4 inhibits glioma proliferation and invasion. J Exp Clin Cancer Res 29: 89, 2010.

13. Gonzalez AM, Podvin S, Lin SY, Miller MC, Botfield H, Leadbeater WE, Roberton A, Dang X, Knowling SE, Cardenas-Galindo E, et al: Ecrg4 expression and its product augurin in the choroid plexus: impact on fetal brain development, cerebrospinal fluid homeostasis and neuroprogenitor cell response to CNS injury. Fluids Barriers CNS 8: 6, 2011.

14. Li L, Zhang C, Li X, Lu S and Zhou Y: The candidate tumor suppressor gene ECRG4 inhibits cancer cells migration and invasion in esophageal carcinoma. J Exp Clin Cancer Res 29: 133,2010

15. Xu T, Xiao D and Zhang X: ECRG4 inhibits growth and invasiveness of squamous cell carcinoma of the head and neck in vitro and in vivo. Oncol Lett 5: 1921-1926, 2013.

16. Jiang CP, Wu BH, Wang BQ, Fu MY, Yang M, Zhou Y and Liu F: Overexpression of ECRG4 enhances chemosensitivity to 5-fluorouracil in the human gastric cancer SGC-7901 cell line. Tumour Biol 34: 2269-2273, 2013.

17. Livak KJ and Schmittgen TD: Analysis of relative gene expression data using real-time quantitative PCR and the 2(-Delta Delta C(T)) Method. Methods 25: 402-408, 2001.

18. Hsiao YC, Hsieh YS, Kuo WH, Chiou HL, Yang SF, Chiang WL and Chu SC: The tumor-growth inhibitory activity of flavanone and $2 \mathrm{-}-\mathrm{OH}$ flavanone in vitro and in vivo through induction of cell cycle arrest and suppression of cyclins and CDKs. J Biomed Sci 14: 107-119, 2007.

19. Ayyagari VN and Brard L: Bithionol inhibits ovarian cancer cell growth in vitro-studies on mechanism(s) of action. BMC Cancer 14: 61, 2014.

20. He L, Lu N, Dai Q, Zhao Y, Zhao L, Wang H, Li Z, You Q and Guo Q: Wogonin induced G1 cell cycle arrest by regulating Wnt/ $\beta$-catenin signaling pathway and inactivating CDK8 in human colorectal cancer carcinoma cells. Toxicology 312: 36-47, 2013.

21. Elmore S: Apoptosis: A review of programmed cell death. Toxicol Pathol 35: 495-516, 2007.

22. Gross A, Jockel J, Wei MC and Korsmeyer SJ: Enforced dimerization of BAX results in its translocation, mitochondrial dysfunction and apoptosis. EMBO J 17: 3878-3885, 1998.

23. Yang D, Chen MB, Wang LQ, Yang L, Liu CY and Lu PH: Bcl-2 expression predicts sensitivity to chemotherapy in breast cancer: A systematic review and meta-analysis. J Exp Clin Cancer Res 32: 105, 2013.

24. Moldoveanu T, Follis AV, Kriwacki RW and Green DR: Many players in BCL-2 family affairs. Trends Biochem Sci 39: 101-111, 2014.

25. Czabotar PE, Lessene G, Strasser A and Adams JM: Control of apoptosis by the BCL-2 protein family: Implications for physiology and therapy. Nat Rev Mol Cell Biol 15: 49-63, 2014.

26. Hall C, Troutman SM, Price DK, Figg WD and Kang MH: Bcl-2 family of proteins as therapeutic targets in genitourinary neoplasms. Clin Genitourin Cancer 11: 10-19, 2013.

27. Barillé-Nion S, Bah N, Véquaud E and Juin P: Regulation of cancer cell survival by BCL2 family members upon prolonged mitotic arrest: opportunities for anticancer therapy. Anticancer Res 32: 4225-4233, 2012.

28. Thornberry NA and Lazebnik Y: Caspases: Enemies within. Science 281: 1312-1316, 1998.

29. Cryns V and Yuan J: Proteases to die for. Genes Dev 12: 1551-1570, 1998

30. Visconti R and D'Adamio L: Functional cloning of genes regulating apoptosis in neuronal cells. Methods Mol Biol 399: 125-131, 2007.

31. Kuribayashi K, Mayes PA and El-Deiry WS: What are caspases 3 and 7 doing upstream of the mitochondria? Cancer Biol Ther 5: 763-765, 2006.

32. Lockshin RA: Programmed cell death: History and future of a concept. J Soc Biol 199: 169-173, 2005 (In French). 